\title{
Reduced Sheep Grazing and Biodiversity: A Novel Approach to Selecting and Measuring Biodiversity Indicators
}

\author{
M. L. Pollock, ${ }^{1}$ J. P. Holland, ${ }^{2}$ C. Morgan-Davies, ${ }^{3}$ J. Morgan-Davies, ${ }^{4}$ and A. Waterhouse ${ }^{5}$ \\ Authors are ${ }^{1}$ Plant Ecologist, ${ }^{2}$ Upland Ecologist, ${ }^{3}$ Livestock Systems Scientist, ${ }^{4}$ Environmental Researcher, and ${ }^{5}$ Head, Hill \& Mountain Research Centre, \\ Future Farming Systems, SRUC Scotland's Rural College, Edinburgh EH9 3JG, Scotland, UK.
}

\begin{abstract}
Traditional upland livestock grazing is declining worldwide, leading to concerns about possible impacts on biodiversity. Although monitoring of protected areas often focuses on rare species, management changes also affect currently common species and vegetation structure. "Biodiversity" is a concept rather than a simple variable, and monitoring it requires indicators that are widely applicable and appropriate to context. This paper presents a novel knowledge-driven approach to developing a selection of biodiversity indicators that can then be rapidly and objectively measured within rangeland environments. Stakeholder and professional opinion on likely changes in biodiversity following reductions in sheep grazing was elicited using a workshop-based process. Potential variables suitable for use as biodiversity indicators were developed and professional opinion on their usefulness sought. A number of indicators were then tested in a natural experiment field study on the impact of reduced sheep grazing in Scotland. In the field study, red deer abundance appeared to increase where sheep grazing was reduced. It was therefore necessary to use estimates of both sheep and deer abundance as explanatory variables. In agreement with the professionals' predictions, dwarf shrub abundance and vegetation height were greater where sheep grazing had been reduced, after taking into account differences in deer. In contrast to the professionals' predictions, the field results showed rough grasses and dead material were less abundant where sheep had been reduced, with deer also having an impact on dead material. The professionals were unsure of the effects of reduced sheep grazing on vegetation mosaic structure; the field results suggested that reduced sheep grazing leads to a reduction in structural heterogeneity, but that deer had the greater impact in this case. Several other predictions showed nonsignificant differences in relation to reduced sheep grazing. The participatory method and some of the field methods presented are cost effective and widely applicable.
\end{abstract}

Key Words: field methods, herbivory, joint learning, rangeland, stakeholder participation, structural heterogeneity

\section{INTRODUCTION}

Upland livestock farming is an integral part of the culture and history of many pastoral areas worldwide. The diverse rangelands created by these farming systems are an important and complex resource for the rural economy (Gordon et al. 2004). Yet throughout the twentieth century, the populations of grazing animals were often considered too high and were believed, for example in large parts of the British uplands, to lead to damage to vegetation and soils (Hallanaro and Usher 2005). Recently however, dramatic changes in rural agriculture and related activities (Moravec and Zemeckis 2007; Bozzolo 2009; Caballero 2009) have highlighted the modern risks of marginalization and the vulnerability of pastoral land to abandonment (Baldock et al. 1996) and with it, the dramatic decline in grazing sheep numbers (MacDonald et al. 2000; IEEP and Veenecology 2005). The uplands of Scotland, an area of mainly marginal pastures, are a good example of this recent and rapid change. Census data shows that the national sheep flock declined by almost 2.9 million between 1998 and 2009, from 9.8 million to 6.9 million (Scottish Government 2010),

\footnotetext{
SRUC receives financial support from the Scottish Government.

Correspondence: Meg Pollock, SRUC Research, Future Farming Systems, West Mains Road, Edinburgh EH9 3JG, Scotland, UK. Email: meg.pollock@sruc.ac.uk
}

Manuscript received 19 July 2011; manuscript accepted 29 January 2013

(c) 2013 The Society for Range Management due to a combination of factors, including a down-turn in economic viability, reductions related to agri-environment scheme management prescriptions, disease outbreaks, and changes in the way that livestock farmers are subsidized (SAC 2008).

The 2003 reform of the European Union Common Agricultural Policy (CAP) decoupled support from production and introduced a Single Payment Scheme subject to cross-compliance rules, including the maintenance of land in Good Agricultural and Environmental Condition (GAEC). These European-level cross-compliance rules (EC Council Regulation 1782/2003) are intended to ensure at least the minimum maintenance of agricultural land, especially that which is no longer used for production. In Scotland, the term "undergrazing" is used in this context, but these cross-compliance rules appear to be poorly defined and to have little or no impact. In practice, on seminatural vegetation it is extremely difficult to define a stage at which the condition of the pasture is passing a threshold into an undergrazed state, particularly as currently described (Scottish Executive 2005).

Traditional low intensity farming practices have created seminatural habitats that can support a more diverse mix of species than purely "natural" climax vegetation habitats (MacDonald et al. 2000). A state where mixed impact grazing by domestic stock under the control of land managers can maintain or develop varied ecological niches need not be considered undesirable (van der Wal 2006) or detrimental to overall conservation and biodiversity targets. 
The long-term effects of reduced sheep grazing on upland biodiversity in the Highlands of Scotland are in part dependent upon the response of wild herbivore populations, particularly red deer (Cervus elaphus L.), to the reduction in competition for forage. If wild herbivore populations and their ranging habits increase to the extent that they exert a similar grazing pressure to that formerly exerted by a combination of domestic sheep and wild herbivores, the resulting change in the landscape is likely to be small (Hope et al. 1996). If there is an overall reduction in grazing pressure, grassland is expected to decline and heathland to increase in abundance, with eventual increases expected in woodland and scrub (Miles 1988) or mire vegetation (Fenton 2008).

Reductions in overall grazing pressure are also likely to lead to a build up of rank swards with an increased likelihood of resulting wildfires. Traditionally in Scotland, selective burning of rank sward and heather has long been included as part of sheep grazing management practices (MacDonald et al. 1998), as well as for red deer and red grouse (Lagopus lagopus scotica) management (Rodwell 1991). As sheep management has reduced, so has the burning regime (in areas without active game management), leading to a situation where random wildfires might be more likely to occur.

Although further declines in sheep numbers within the seminatural hill areas in Scotland are occurring (MorganDavies and Waterhouse 2008), there has been little sign of alternative agriculture or other domestic grazing activities. Moreover, the upland habitats used for sheep grazing, primarily acid grasslands and wet and dry heath, are valued by the public for the open vistas they provide (Morgan-Davies et al. 2003). Some of these habitats are internationally recognized for their biodiversity and are designated for the flora (e.g., alpine and subalpine calcareous grasslands) or fauna living there (e.g., European Union Birds Directive Annex 1 species).

"Biodiversity" is a concept (Wilson and Peter 1988) and not a simple variable that can be measured. People's perceptions of landscapes are also different (Rogge et al. 2007) and perceived changes are largely value-driven. It is crucial therefore to assess a wide range of opinions regarding the likely impacts of reduced sheep grazing and what indicators of biodiversity change would be most appropriate to study and measure in the field. For these reasons, a participatory approach to the design process, combining both professionals and stakeholders, is considered to be most useful, because this allows the inclusion of a wide range of views that would more likely characterize and validate the issue robustly than a purely science-driven approach (Cannon and Surjadi 2004; Bracke et al. 2007; Stilma et al. 2007; Soliva et al. 2008). Indeed, as Reed (2008) points out in his detailed review, there is evidence that the quality of environmental decisions can be enhanced by stakeholder participation through the consideration of more comprehensive information inputs. This approach therefore has longer lasting merit, because as well as focusing and stimulating people's interest in the topic in a widely applicable joint learning environment (Ravnborg and Westermann 2002; Knapp et al. 2011), the participatory process ensures that biodiversity data collected in the field, using methods considered appropriate, would have a strong long-term value as well as being relevant to the participants' views. From a more global standpoint, a stakeholder-driven participatory approach would therefore be an appropriate method for determining biodiversity indicators in any rangeland ecosystem in the world.

Using the population size of individual species of conservation interest as biodiversity indicators (Noss 1990) often is not practical, because rare species, by definition, are not ubiquitous. Instead, the variables developed have to be easy to measure, both rapidly and accurately in the field, while having the widest biodiversity significance and being applicable to a wide variety of sites. Reduced sheep grazing is likely to have an impact on a varied range of upland habitats. The methods developed in this study were therefore deliberately planned to be generally applicable rather than being site-specific and detailed.

The overall aim of this study was to develop practical indicators of the impacts of reduced sheep grazing on upland biodiversity through consultation with professionals. The approach involved four consecutive steps: 1) a workshop to elicit the predictions of professionals on the impacts of reduced sheep grazing; 2) development of a set of biodiversity indicators; 3) measurement of these indicators in the field; and 4) evaluation of the workshop predictions against the field study results.

\section{METHODS}

Our method used a participatory approach to develop a set of biodiversity indicators, followed by a field study to test the indicators. Given the slow responses of vegetation to changes in grazing pressure, a comparative field study at several paired sheep grazing sites (where sheep numbers had remained stable in one location and where sheep numbers had reduced nearby) was deemed most useful. The chosen study habitat type and location was open hill ground (acid grassland, and wet and dry heath) above the altitudinal limit of bracken (Pteridium aquilinum [L.] Kuhn). Such habitats are extensive (Norton et al. 2009), of interest to tourists, and have been traditionally grazed for long periods of time and therefore have similar issues to many of the rangeland resources of the world.

\section{Development of Potential Biodiversity Indicators by Professionals}

Stage One-Workshop. Thirty workshop participants attended a meeting in Glencoe (Western Highlands of Scotland) in April 2006 (Table 1). The participants were either from government agencies, nongovernmental organizations, or were other professionals with an interest in upland conservation and management.

Using the workshop facilitation techniques suggested by Hogan (2003) and French (2006), which include brainstorming, consensus, and decision-making processes, the attendees were randomly allocated into three groups of 10 and then presented with a case-study scenario. The scenario represented a typical mixed-grazing Scottish Highland hill farm of approximately 1000 ha in the western portion of the country with vegetation dominated by acid grassland, with year-round sheep grazing at 1 ewe $\cdot \mathrm{ha}^{-1}$ and limited summer cattle grazing, reducing to 0.25 ewes $\cdot \mathrm{ha}^{-1}$ and no cattle, with deer being present but in low numbers. Each participant was then asked to predict the outcome of reduced livestock grazing by answering 
Table 1. Employment types and areas of expertise of the professionals who contributed to the two stages of the development of the biodiversity indicators.

\begin{tabular}{|c|c|c|}
\hline Stage & Employment type $^{1}$ & Area of expertise \\
\hline \multirow[t]{10}{*}{ Stage one: workshop } & Industry professionals & Agriculture \\
\hline & Research scientists & Upland ecology \\
\hline & Research scientists & Mountain environments and people \\
\hline & NGO/charity & Upland land management and conservation \\
\hline & Government agency & Nature conservation and uplands \\
\hline & Research scientists & Upland research (ecology and land use) \\
\hline & Land Agents & Land management \\
\hline & NGO/charity & Nature conservation \\
\hline & NGO & Nature conservation and land management \\
\hline & Government agency & Environmental protection \\
\hline \multirow[t]{9}{*}{ Stage two: questionnaire } & Research scientists & Upland research (ecology and land use) \\
\hline & NGO/charity & Upland land management and conservation \\
\hline & NGO/charity & Habitat and bird conservation \\
\hline & Research scientists & Upland ecology \\
\hline & Research scientists & Forest conservation and management \\
\hline & Local government biodiversity officer & Biodiversity management \\
\hline & Government agency & Forestry management \\
\hline & Government agency & Nature conservation and uplands \\
\hline & NGO/charity & Woodland conservation and management \\
\hline
\end{tabular}

${ }^{1} \mathrm{NGO}$ indicates Nongovernmental Organization.

this question: "How will vegetation and other forms of biodiversity change in response to the new management?" The individual predictions for change were then shared with their group, discussed and voted upon for relevance before being presented in summary to all attendees (Table 2).

The study team then assessed the variables listed (Table 2) for their potential use as biodiversity indicators. A number of variables were rejected on the basis that they were rare in the study zone or were beyond the scope of this study. Furthermore, the potential variable labeled "deer" from the workshop was rejected as an indicator because it was to be used in the later analysis as an explanatory variable. The outcome of this exercise was a list of 10 potential indicators (Table 2) that could indicate changes in biodiversity (henceforth referred to as the potential "biodiversity indicators").

Stage Two-Questionnaire. Six of the 10 potential biodiversity indicators (those not relating to groups of plant species) (Table 2) were subsequently analyzed by a different professional group (Table 1) via a questionnaire. The professionals were ecological researchers, scientists, and relevant attendees at a conference titled "The Future of Biodiversity in the Uplands" (organized by Perth College Centre for Mountain Studies and held at Battleby, Scotland on 8 December 2006). The questionnaire asked the respondents to review the six possible biodiversity indicators in terms of their usefulness for landscape-scale assessments. The possible indicators needed to be simple and robust enough to rapidly assess in the field with limited resources. Each professional was asked to categorize the indicators as essential to measure, useful to measure, or not useful to measure (Table 3). Because the individuals whose opinions were elicited in stage two comprised a higher proportion of scientists than those in stage one, we felt that it was appropriate to ask them to comment on the proposed indicators. Being scientists with expertise in experimental field work, we considered that their practical experience would help them to visualize the proposed field methods and allow them to judge the potential indicators in a way that the original group, which contained a much smaller proportion of scientists, would possibly have struggled with. Seventeen responses were obtained.

Stage Three-Final Selection of Biodiversity Indicators. In spite of many of the stage two professionals describing the variable "birds" as essential to measure, the study team unfortunately had to remove it from the final list, because measurement of this variable was beyond the resources available. Although dead material was deemed the least important variable considered by the stage two professionals (only 25\% regarded it as essential), it was included in the field analysis because the build up of dead material (or "thatch") is mentioned under the Scottish GAEC cross-compliance rules (Scottish Executive 2005). To reduce the time required to complete the questionnaire, we did not ask the professionals at the conference about the suitability of using changes in species groups (the four indicators: dwarf shrubs, rough grasses, sweet grasses, and herb species). The variables relating to plant species groups were deemed by the study team to be essential and therefore were included without offering the stage two professionals the opportunity to comment on them. The final set of nine biodiversity indicators (those in the last column in Table 2) were then tested for applicability by measurement in the field.

\section{Study Sites}

Potential study sites were selected by consulting the professionals and the workshop participants, and by telephoning contacts in the uplands. Criteria for choosing sites were as follows: a) a hirsel (area grazed by one flock of sheep) where sheep grazing had been reduced or removed in the last 2 to 20 yr ("reduced" subsite), and b) where there was an adjacent or 


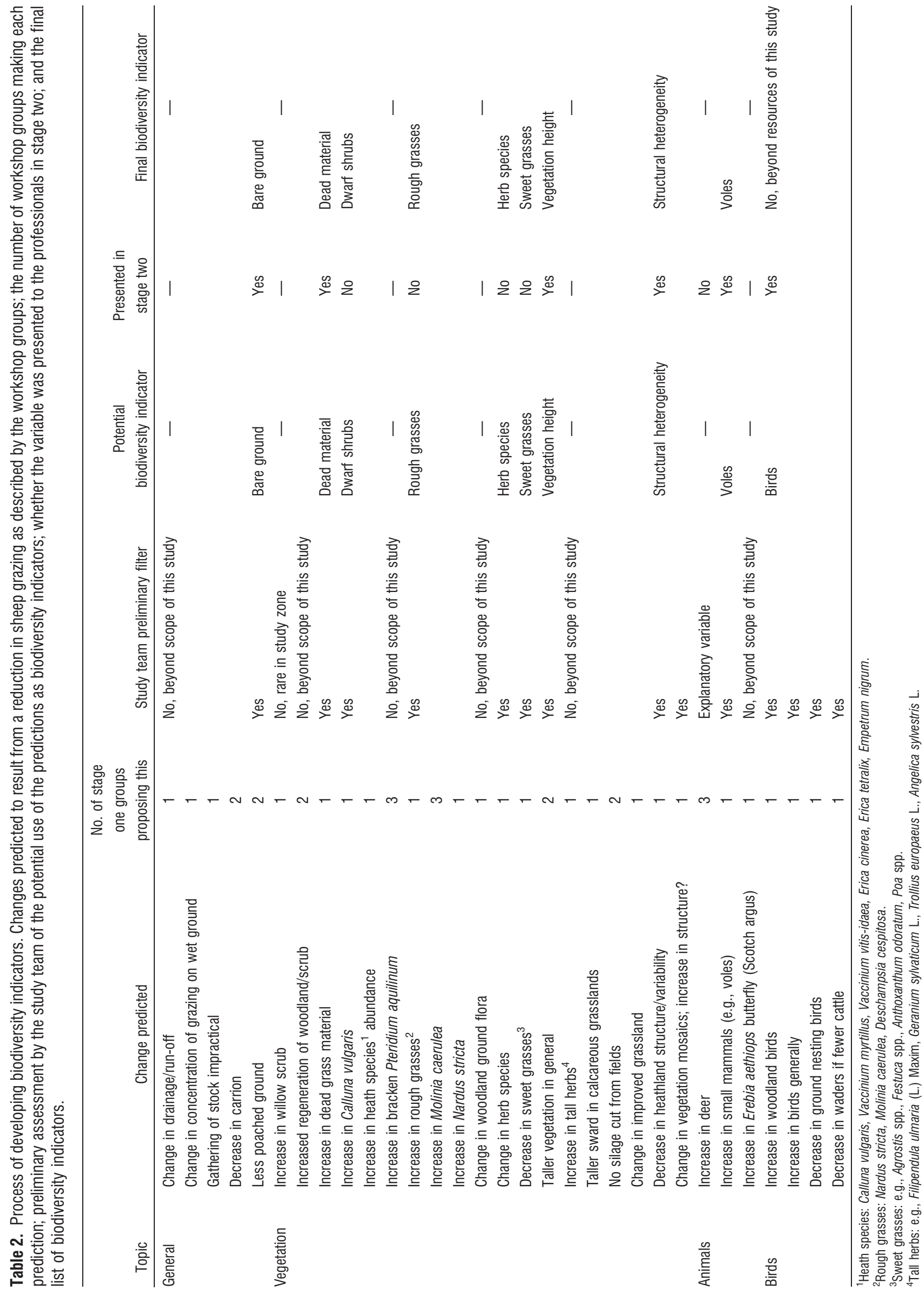


Table 3. Summary of professionals' opinion on the usefulness of the potential biodiversity indicators (ranked as Essential, Useful or Not Useful) with one vote each (as proportion of total votes). The indicators are arranged with those achieving the greatest proportion of essential votes in the left-most column through to those with the least in the right-most column. Votes assigned to intermediate rankings by the professionals have been combined in equal share to their nearest neighbors. The professionals were only invited to comment on potential indicators not relating to groups of plant species.

\begin{tabular}{lcccccc}
\hline Usefulness of measure & $\mathrm{SH}^{1}$ & Birds & Bare ground & Vegetation height & Voles & Dead material \\
\hline Essential & 0.79 & 0.56 & 0.47 & 0.44 & 0.37 & 0.25 \\
Useful & 0.18 & 0.25 & 0.27 & 0.44 & 0.43 & 0.36 \\
Not useful & 0.03 & 0.19 & 0.26 & 0.12 & 0.20 \\
\hline
\end{tabular}

${ }^{1} \mathrm{SH}$ indicates structural heterogeneity.

nearby hirsel with similar topography where grazing had continued ("continued" subsite).

The twelve selected sites were on hill ground with vegetation dominated by acid grassland (Nardus stricta [L.] or Molinia caerulea [L.] Moench) or wet or dry heath, with no cattle present recently. Two sampling areas (minimum size 12 ha, between $350 \mathrm{~m}$ and $750 \mathrm{~m}$ above mean sea level) within each site (the subsites) were then identified (Table 4) and matched as far as possible for altitude, slope, aspect, and geology. Sampling areas were located to exclude montane communities, areas dominated by bracken, and areas with evidence of wildfires. Of the sites chosen for study, five had some form of controlled burning (Table 4), but three of these sites ( $S h, T r$, and GL) had been burnt on only one subsite of the pair. The burning at $S h$ and $\operatorname{Tr}$ was part of the ongoing sheep grazing management. These sites were included because vegetation burning is a common tool for sheep grazing management in the Scottish Highlands, and a reduction in the burning regime often follows a reduction in sheep grazing management. At GL, burning was used in the reduced grazing subsite as a management tool for game (red deer and red grouse). Although the continued sheep grazing subsite at GL did not have on-going burning management, the site was included because the reduction in sheep numbers had been dramatic and it was considered that the impact of this change was likely to be greater than that of the burning regime. The vegetation sampled at the GL reduced site had not been recently burned.

Table 4. Detailed characteristics of the 12 pairs of sites (24 subsites).

\begin{tabular}{|c|c|c|c|c|c|c|}
\hline Site code & Subsite category ${ }^{1}$ & Area (ha) & Hill vegetation type ${ }^{2}$ & Presence of burning & Year of reduction & $\begin{array}{c}\text { Sheep stocking density } \\
2007\left(\text { ewes } \cdot \text { ha }^{-1} \text { ) }\right.\end{array}$ \\
\hline \multirow[t]{2}{*}{ At } & $r$ & 7518 & $\mathrm{H}-\mathrm{G}$ mosaic & Yes & 1987 & $<0.1$ \\
\hline & c & 2387 & $\mathrm{H}-\mathrm{G}$ mosaic & Yes & - & 0.2 \\
\hline \multirow[t]{2}{*}{$B L$} & $r$ & 1300 & Grass & No & 1996 & 0.6 \\
\hline & c & 420 & Grass & No & - & 1.6 \\
\hline \multirow[t]{2}{*}{ Bo } & $r$ & 820 & Grass & No & 1995 & 0.2 \\
\hline & c & 650 & Grass & No & - & 0.6 \\
\hline \multirow[t]{2}{*}{$G L$} & $r$ & 2300 & $\mathrm{H}-\mathrm{G}$ mosaic & Yes & 2005 & 0.0 \\
\hline & c & 1830 & $\mathrm{H}-\mathrm{G}$ mosaic & No & - & 0.5 \\
\hline \multirow[t]{2}{*}{ Gs } & $r$ & 3917 & $\mathrm{H}-\mathrm{G}$ mosaic & Yes & 2000 & 0.0 \\
\hline & c & 1636 & $\mathrm{H}-\mathrm{G}$ mosaic & Yes & - & 0.3 \\
\hline \multirow[t]{2}{*}{$K i$} & $r$ & 36 & Grass & No & 1999 & 0.0 \\
\hline & c & 558 & Grass & No & - & 0.9 \\
\hline \multirow[t]{2}{*}{$\mathrm{Pi}$} & $r$ & 944 & $\mathrm{H}-\mathrm{G}$ mosaic & Yes & 1993 & 0.0 \\
\hline & c & 640 & $\mathrm{H}-\mathrm{G}$ mosaic & Yes & - & 0.9 \\
\hline \multirow[t]{2}{*}{ Ra } & $r$ & 350 & Grass & No & 1997 & 0.0 \\
\hline & c & 1359 & Grass & No & - & 0.3 \\
\hline \multirow[t]{2}{*}{ Sh } & $r$ & 860 & $\mathrm{H}-\mathrm{G}$ mosaic & No & 2000 & 0.1 \\
\hline & c & 470 & $\mathrm{H}-\mathrm{G}$ mosaic & Yes & - & 1.0 \\
\hline \multirow[t]{2}{*}{ Ta } & $r$ & 259 & $\mathrm{H}-\mathrm{G}$ mosaic & No & 1998 & 0.0 \\
\hline & C & 509 & $\mathrm{H}-\mathrm{G}$ mosaic & No & - & 0.6 \\
\hline \multirow[t]{2}{*}{$\operatorname{Tr}$} & $r$ & 810 & $\mathrm{H}-\mathrm{G}$ mosaic & No & 2002 & 0.0 \\
\hline & c & 430 & $\mathrm{H}-\mathrm{G}$ mosaic & Yes & - & 0.6 \\
\hline \multirow[t]{2}{*}{ Ty } & $r$ & 240 & Grass & No & 2004 & 0.7 \\
\hline & c & 450 & Grass & No & - & 0.7 \\
\hline
\end{tabular}

${ }^{1} \mathrm{r}$ indicates reduced sheep grazing; $\mathrm{c}$ indicates continued sheep grazing.

${ }^{2} \mathrm{H}-\mathrm{G}$ mosaic indicates heather-grass mosaic sites with more than $8 \%$ heather on transects; Grass indicates grass-dominated sites with up to $8 \%$ heather on transects.

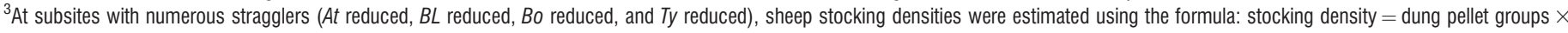
0.01025 . This formula was generated by doing linear regression on the sheep stocking density and observed sheep dung pellet groups for the 20 subsites with good information on sheep stocking density. At all other subsites, land managers provided information on sheep numbers and hirsel areas. 
The unit area, current sheep population, and date of any reduction in sheep numbers (Table 4 ) were supplied by the land managers responsible for each hirsel. The time since sheep reduction varied between 2 and 20 yr. The estimated sheep stocking density varied from 0 to 0.7 ewes $\cdot \mathrm{ha}^{-1}$ at reduced grazing sites, and from 0.2 to 1.6 ewes $\cdot \mathrm{ha}^{-1}$ at continued grazing sites. Within each sampling area, five random points (a logistically feasible set of surveys for each subsite) were then generated using ArcMap geographic information system (GIS) tools (ESRI 2007).

\section{Field Measurements}

As a means of rapidly describing the vegetation present, the transect method of Phillips (1989) was modified to include a description of the structure of the vegetation in each patch. Transect data were obtained from the two subsites at each of the five random points during the growing season of 2007 (June to September, inclusive). Subsite pairs were sampled within $5 \mathrm{wk}$ of each other to minimize any seasonal effects. A total of 120 transects were surveyed: 12 sites $\times 2$ subsites $\times 5$ transects.

From each random start point, a 100-m measuring tape was laid out, running across the slope and maintaining a level altitude as far as possible. Starting at $0 \mathrm{~m}$, the observer recorded the vegetation type, using the National Vegetation Classification (NVC; Rodwell 1991, 1992), the dominant plant species (maximum of four), and the topography (stream, flush, slope, knoll, ridge, hollow, or flat) of the vegetation patch bisected by the transect line. The dominant and subdominant vegetation structure types within the patch were also noted (smooth grass, tufted grass, tussock grass, carpet dwarf shrub heath, pioneer dwarf shrub heath, topiary dwarf shrub heath, building dwarf shrub heath, mature dwarf shrub heath, overmature dwarf shrub heath, bryophyte carpet, bracken). A representative height of the dominant and subdominant structure was recorded using a cane marked in height bands $(0.0 \mathrm{~cm}$ to $5.0 \mathrm{~cm}, 5.1 \mathrm{~cm}$ to $10.0 \mathrm{~cm}, 10.1 \mathrm{~cm}$ to $15.0 \mathrm{~cm}, 15.1$ $\mathrm{cm}$ to $20.0 \mathrm{~cm}, 20.1 \mathrm{~cm}$ to $30.0 \mathrm{~cm}, 30.1 \mathrm{~cm}$ to $50 \mathrm{~cm}, 50.1 \mathrm{~cm}$ to $100 \mathrm{~cm})$. Bare ground cover and rock cover were recorded on a categorical scale $(0 \%, 1-25 \%, 26-50 \%, 51-75 \%$, $>75 \%)$. The observer then traversed the transect, repeating the recording each time there was either a change in vegetation type, dominant species composition, or structure, and recording the distance from the start. Only patches greater than $1 \mathrm{~m}$ long that crossed the transect line were recorded, unless they were connected to a larger patch. The observer also counted the sheep and/or deer dung pellet groups (defined as a cluster of six or more pellets apparently produced at the same defecation; Mayle et al. 1999) within $50 \mathrm{~cm}$ either side of the center line. Each transect therefore included dung counts for an area of 100 $\mathrm{m}^{2}$. The sheep and deer dung counts used later in the analysis were the sum totals from all five transects in each subsite. This simple method provided information on relative herbivore abundance that could be measured quickly in the field. Ideally we would have followed the methods of Latham et al. (1996) by sampling multiple transects until a stable cumulative average value was achieved, but time constraints precluded this. A single herbage height was measured using a sward stick (Barthram 1986) $20 \mathrm{~cm}$ uphill of the measuring tape every $2 \mathrm{~m}$ along the transect, recording height, species (including "rock", "bare ground," and "water"), and whether living or dead. Further, a $2 \times 2 \mathrm{~m}$ quadrat was laid out at the end of each transect and the percentage cover of each vascular plant species, total bryophytes, and bare ground was estimated by eye. The presence of holes or runways created by field voles (Microtus agrestis L.) within the quadrat was also recorded.

\section{Data Analysis}

Dung Counts and Sheep Stocking Density. In order to assess whether sheep dung pellet groups provided a good estimate of sheep grazing pressure, and to check how accurately sheep and deer dung had been distinguished, known sheep stocking densities were correlated with the three herbivore pellet group counts (sheep, deer, and total) recorded at each subsite. Note that four subsites known to have considerable numbers of straggler sheep (that is, sheep straying in from neighboring hirsels or farms) were excluded from this part of the analysis.

Subsite Summaries of Biodiversity Indicators. Vole signs were the sum of the number of quadrats per subsite that had signs of voles. Dwarf shrub abundance was estimated as the proportion of sward stick hits to dwarf shrubs (Calluna vulgaris [L.] Hull., Vaccinium myrtillus L., Vaccinium vitisidaea L., Erica cinerea L., Erica tetralix L., and Empetrum nigrum L.), out of the total sward stick hits per subsite. Similarly, the abundance of rough grasses (Nardus stricta, Molinia caerulea, and Deschampsia cespitosa [L.] P. Beauv.), sweet grasses (Agrostis spp., Anthoxanthum odoratum L., Festuca ovina L., Festuca rubra L., Festuca vivipara auct. non [L.] Sm., and Poa spp.) and herb species (nongramminoid flowering species without woody stems) was calculated using the same method. Vegetation height was the mean of the heights of sward stick hits to plant material (bare ground, rock, and water were excluded) at each subsite. Dead material was the sum of the number of sward stick hits to dead material at each subsite. Bare ground was summarized for each subsite by calculating the proportion of patches that contained any sward stick hits to bare ground.

Structural heterogeneity was calculated as follows. For each vegetation patch, a compound description of dominant and subdominant structure with dominant and subdominant heights (in $\mathrm{cm}$ ) was formed using the "Concatenate" function in Microsoft Excel. For instance, if a patch had a dominant structure of "Dwarf Shrub," height "6-10," with a subdominant structure of "Bryophytes," height " $0-5$," the compound description would be: "Dwarf Shrub6-10Bryophytes0-5." The total number of different compound types that occurred in each subsite was then used as a measure of subsite level spatial and structural heterogeneity: the higher the number of occurring heights and structures, the more heterogeneous was the vegetation, at the hirsel scale. The method for measuring structural heterogeneity was created after the field surveying was completed.

Analysis of Biodiversity Indicators in Relation to Herbivore Dung. At one site (Ty), the amount of sheep dung was actually slightly higher in the reduced subsite than in the continued subsite, due to straggler sheep (Fig. 1). At four other sites, the greater abundance of deer dung where sheep grazing had been reduced (Bo, $A t, P i$, and $G S$ in Fig. 1) meant that the total dung 
counts in the "reduced" subsite were greater than or equal to those in the "continued" subsite. This apparent interaction between sheep and deer, and the wide variation between sites in sheep stocking density (Table 4), meant that comparing the mean values for the biodiversity indicators at all reduced and continued subsites would have been misleading. It was therefore necessary to summarize the data on herbivore densities and biodiversity indicators by calculating the differences between the pairs of subsites. We named the explanatory variables relating to herbivore dung the "sheep dung index" and "deer dung index." We applied the formula $\Delta_{\mathrm{x}}=\mathrm{x}_{\mathrm{r}}-\mathrm{x}_{\mathrm{c}}$, where $\Delta$ was "difference in"; x was the herbivore dung or biodiversity indicator in question; $r$ was the "reduced sheep grazing" subsite, and c was the "continued sheep grazing" subsite.

For example, for the deer dung index, the number of deer pellet groups for the continued sheep grazing subsite was subtracted from the number of deer pellet groups for the reduced sheep grazing subsite: $\boldsymbol{\Delta}_{\text {deer dung }}=$ deer dung $_{\mathrm{r}}-$ deer dung. $_{\mathrm{c}}$. Note that this method focuses on observed differences between subsite pairs. A positive deer dung index value shows that deer dung abundance was greater where sheep grazing had been reduced than where sheep grazing was continued.

Statistical Modeling. Multiple linear regression was used to assess the individual and combined impact of the two explanatory variables (the sheep dung index and the deer dung index) on each of the biodiversity indicator indices. This resulted in three possible models (sheep dung index only, deer dung index only, and sheep dung index plus deer dung index) for each biodiversity indicator index; the model with the lowest $P$ value and which accounted for the greatest percentage of variation was selected as the "best fit." Data analysis was carried out using Genstat 10 (VSNi 2007).

\section{RESULTS}

\section{Workshop Predictions and Assessment of Biodiversity Indicators by Professionals}

The workshop participants predicted that reduced sheep grazing was likely to result in an increase in deer and voles, and that the changes in vegetation would include: an increase in dwarf shrubs and rough grasses; taller vegetation in general; an increase in dead material; and a possible increase in the structure of vegetation mosaics, but a decrease in heathland structure or variability (Table 2). All three groups predicted that deer, Molinia caerulea (one of the rough grasses), and bracken would increase following a reduction in livestock grazing (Table 2). Other predictions were made by only one or two groups.

There was general agreement among the professionals that spatial and structural heterogeneity was an essential biodiversity indicator. Birds were viewed as the second best indicator, with over half of the professionals describing this variable as "essential." Otherwise, there was considerable variability among the professionals in the way they categorized the variables (Table 3 ).

\section{Accuracy in Assessing Sheep and Deer Presence}

The correlation between observed sheep dung and reported sheep stocking density (for the 20 subsites with good

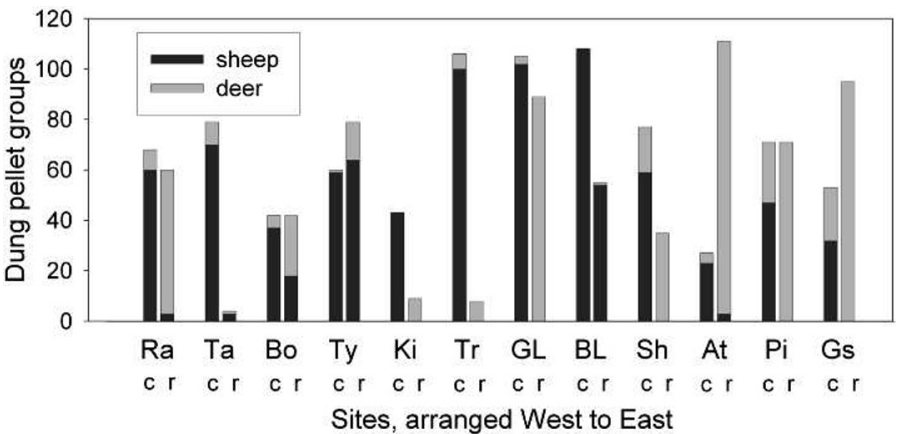

Figure 1. Total dung pellet groups (sheep and deer) present at subsites "c" (sheep continued) and " $r$ " (sheep reduced). Study sites explained in Table 4.

information on sheep stocking density) was positive and relatively strong $(r=0.775, P<0.01)$, whereas deer dung and sheep stocking density were negatively, and less strongly, correlated $(r=-0.485, P<0.05)$. Total dung and sheep stocking density were positively correlated $(r=0.440, P=$ 0.05 ) but much less so than sheep dung and sheep stocking density. Also, the sheep dung index $\left(\Delta_{\mathrm{s}}\right)$ and the deer dung index $\left(\Delta_{\mathrm{d}}\right)$ were not correlated with each other $(r=0.071, P=$ $0.83)$. These results suggest that sheep and deer dung were being accurately distinguished most of the time and could therefore be considered as distinct parameters for the later analysis.

\section{Sheep and Deer Dung Counts}

At a majority of sites (Fig. 1) deer appeared to be more abundant where sheep grazing had been reduced than where it had continued. At one site, Ty, more sheep dung was found in the reduced subsite than in the continued subsite. This was due to neighboring sheep moving into the reduced site. Unexpectedly, there were also several instances where the reduced subsites had more total dung (sheep + deer) present than the subsites with continued sheep grazing; this was most notable at At and Gs where large quantities of deer dung were found (Fig. $1)$.

\section{Associations Between Herbivore Dung Indices and Biodiversity Indicator Indices}

Models using both the deer dung index and the sheep dung index as explanatory variables generally explained more of the variation in the biodiversity indicator indices than those using one herbivore dung index alone; the exceptions were the rough grasses index and the bare ground index (Table 5). For example, the model using both the sheep dung index and the deer dung index explained much more of the variation in the dwarf shrub index than did the sheep dung index alone (Table $5)$.

The negative relationships between the dwarf shrub index and the herbivore dung indices (Table 5) suggests that when reductions in both sheep and deer grazing occur, dwarf shrub cover (predominantly heather, Calluna vulgaris) is likely to increase. The vegetation height index and the herbivore dung indices were also negatively related (Table 5), as expected, implying that reductions in both sheep and deer grazing are 
Table 5. Associations between dung indices and biodiversity indicator indices. Results of linear regression using the sheep dung index only and the deer dung index only and multiple linear regression using both the sheep dung index and the deer dung index as explanatory variables. Models providing the best fit are in bold.

\begin{tabular}{|c|c|c|c|c|c|c|c|}
\hline \multirow[b]{3}{*}{$\begin{array}{l}\text { Biodiversity indicator indices } \\
\quad \text { (response variables): }\end{array}$} & \multicolumn{6}{|c|}{ Explanatory variables included in model } & \multirow[b]{3}{*}{$\begin{array}{l}\text { Trend of variable(s) } \\
\text { giving best fit }\end{array}$} \\
\hline & \multicolumn{2}{|c|}{$\begin{array}{c}\text { Sheep dung } \\
\text { index only }\left(\boldsymbol{\Delta}_{\mathrm{S}}\right)\end{array}$} & \multicolumn{2}{|c|}{$\begin{array}{c}\text { Deer dung } \\
\text { index only }\left(\boldsymbol{\Delta}_{\mathrm{d}}\right)\end{array}$} & \multicolumn{2}{|c|}{$\begin{array}{c}\text { Sheep dung index and } \\
\text { deer dung index }\left(\boldsymbol{\Delta}_{\mathrm{s}}+\boldsymbol{\Delta}_{\mathrm{d}}\right)\end{array}$} & \\
\hline & $P$ value & $\begin{array}{c}\text { \% variance } \\
\text { explained }\end{array}$ & $P$ value & $\begin{array}{l}\% \text { variance } \\
\text { explained }\end{array}$ & $P$ value & $\begin{array}{l}\text { \% variance } \\
\text { explained }\end{array}$ & \\
\hline Vole presence ${ }^{1}$ & $\mathrm{NS}^{3}$ & - & NS & - & NS & - & - \\
\hline Dwarf shrub abundance ${ }^{2}$ & $P<0.05$ & 35.6 & NS & - & $P<0.05$ & 59.1 & Both Negative \\
\hline Rough grass abundance ${ }^{2}$ & $P<0.005$ & 56.7 & NS & - & $P<0.05$ & 52.0 & Positive \\
\hline Sweet grass abundance ${ }^{2}$ & NS & - & NS & - & NS & - & - \\
\hline Herb species abundance ${ }^{1}$ & NS & - & NS & - & NS & - & - \\
\hline Vegetation height $^{2}$ & NS & - & NS & - & $P<0.05$ & 43.5 & Both Negative \\
\hline Dead material $\left.\right|^{2}$ & NS & - & $P<0.05$ & 42.9 & $P<0.05$ & 57.9 & Both Positive \\
\hline Bare ground ${ }^{2}$ & NS & - & $P<0.005$ & 53.8 & $P<0.05$ & 48.6 & Positive \\
\hline Structural heterogeneity ${ }^{2}$ & NS & - & $P<0.05$ & 36.2 & $P<0.05$ & 46.8 & Both Positive \\
\hline
\end{tabular}

${ }^{1}$ Index derived from quadrat data.

${ }^{2}$ Index derived from transect data.

${ }^{3} \mathrm{NS}$ indicates not significant.

likely to lead to increases in vegetation height. The positive association between the sheep dung index and the rough grasses index implies that dwarf shrubs are expanding at the expense of rough grasses where sheep grazing has reduced.

Contrary to expectations, the dead material index was positively related to the sheep dung and deer dung indices (Table 5). This implies a decrease in dead herbage material if sheep and deer grazing were reduced. Further analysis of the data on dead material in which dead dwarf-shrub material was excluded showed that the difference in percentage of remaining dead material between pairs of subsites was very small (although there was still a small positive trend with dung). It would appear that sampling of recently burned patches at dwarf-shrub-dominated sites, which had a high proportion of hits to dead dwarf-shrub material, might have produced these results.

The model using both sheep and deer dung indices to predict changes in the structural heterogeneity index provided the best fit, although the model using deer dung index alone was also significant (Table 5). The bare ground index and the deer dung index were also positively related, suggesting that decreased deer grazing might cause decreases in the amount of bare ground. Although the model using both the sheep and deer dung indices to predict the bare ground index was also significant, it was less so than that using the deer dung index alone. The sheep and deer dung indices were not significantly related to the vole index, the sweet grass index, or the herb species index (Table 5). The vole index had nonsignificant negative trends with the sheep index and deer index.

\section{Comparison of Workshop Predictions with Field Measurements}

The workshop participants predicted an increased presence of deer if sheep grazing was reduced, which evidence from the field study supported (Fig. 1). The field study also confirmed the workshop participants' predictions that reduced sheep grazing would result in increased abundance of dwarf shrubs (especially heather) and increased vegetation height (Table 6). However, the field study results contradicted the workshop participants' predictions about increases in rough grasses and dead material. The field study results also contradicted the workshop participants' predictions about the biodiversity indicator indices that were found to have nonsignificant relationships with the sheep dung index: voles, sweet grasses, herb species, and bare ground (Table 6). In fact, neither of the biodiversity indicators measured using quadrats (voles and herb species) generated significant results. The workshop participants were unsure about the impact of reduced sheep grazing on structural heterogeneity, and the questionnaire respondents felt it was an essential variable to measure, the field study results showed that reduced sheep grazing (with reduced deer grazing) was associated with reduced structural heterogeneity.

\section{DISCUSSION}

\section{Participant Predictions and Field Results}

The workshop participants were asked to predict important changes in biodiversity following a reduction in upland sheep grazing. The workshop helped to stimulate interest in the subject for a variety of stakeholders and was an opportunity for joint learning (Bouma 2001; Knapp et al. 2011). As expected, there was variation among individuals' opinions (Pollock et al. 2007) and not all groups made the same predictions.

After excluding a number of predictions that were outside the scope of the study, potential biodiversity indicators were developed from the predictions, and a number of potential indicators were evaluated by other professionals. Nine biodiversity indicator variables were then tested in the field. The excluded predictions (Table 2) were general ones relating to carrion, hydrology and livestock management, predictions about relatively rare species or communities (montane scrub, tall herbs), those not relating to the submontane zone (bracken, woodland flora), and those relating to birds or invertebrates 
Table 6. Impact of reduced sheep grazing: professionals' predictions, field results, authors' comments on the field study results and relevant evidence from literature.

\begin{tabular}{|c|c|c|c|}
\hline $\begin{array}{l}\text { Professionals' } \\
\text { prediction }\end{array}$ & Field result & Comments & Literature \\
\hline Voles will increase. & $\begin{array}{l}\text { NS. }{ }^{1} \text { Trend in agreement with } \\
\text { prediction. }\end{array}$ & $\begin{array}{l}\text { Sample size ( } 5 \text { quadrats per subsite) } \\
\text { probably too small. }\end{array}$ & $\begin{array}{l}\text { Hope et al. (1996), Smit et al. (2001), } \\
\text { Steen et al. (2005), and Evans et } \\
\text { al. (2006) all support the } \\
\text { professionals' predictions. }\end{array}$ \\
\hline Dwarf shrubs will increase. & $\begin{array}{l}\text { Yes. Less sheep grazing and less } \\
\text { deer grazing was associated with } \\
\text { greater dwarf shrub abundance. }\end{array}$ & - & $\begin{array}{l}\text { Hulme et al. (2002) support a gradual } \\
\text { increase. }\end{array}$ \\
\hline Rough grasses will increase. & $\begin{array}{l}\text { No. Less sheep grazing was } \\
\text { associated with a decrease in } \\
\text { rough grass abundance. }\end{array}$ & - & $\begin{array}{l}\text { Pakeman et al. (2003) support the } \\
\text { field result. Hulme et al. (1999) and } \\
\text { Hill et al. (1992) observed } \\
\text { increases in the cover of } M \text {. } \\
\text { caerulea but decreases in } N \text {. stricta } \\
\text { following the exclusion of livestock } \\
\text { from areas of Festuca-dominated } \\
\text { hill grassland. }\end{array}$ \\
\hline Sweet grasses will decrease. & NS. No trend observed. & $\begin{array}{l}\text { Field result reliable (sweet grasses } \\
\text { were assessed along transects; } \\
\text { therefore, observable differences } \\
\text { should have been detectable if } \\
\text { present). }\end{array}$ & $\begin{array}{l}\text { Grant et al. (1996) tentatively support } \\
\text { the prediction; a trend toward } \\
\text { increased sweet grass cover under } \\
\text { relatively heavy sheep grazing was } \\
\text { observed. }\end{array}$ \\
\hline Change in herb species. & NS. No trend observed. & $\begin{array}{l}\text { Field results might relate to sampling } \\
\text { methods (only five quadrats per } \\
\text { subsite sampled). }\end{array}$ & $\begin{array}{l}\text { DeGabriel et al. (2011) found reduced } \\
\text { plant diversity where sheep were } \\
\text { absent. Miller et al. (2010) found a } \\
\text { reduction in annual forbs and slight } \\
\text { increases in perennial forbs (herbs) } \\
\text { where sheep were excluded. }\end{array}$ \\
\hline Vegetation will become taller. & $\begin{array}{l}\text { Yes. Less sheep grazing and less } \\
\text { deer grazing was associated with } \\
\text { greater vegetation height. }\end{array}$ & - & $\begin{array}{l}\text { Hope et al. (1996), Miller et al. } \\
\text { (2010), and Mayer et al. (2009) all } \\
\text { agree with the increase in sward } \\
\text { height. However DeGabriel et al. } \\
\text { (2011) found that heather was } \\
\text { shorter where sheep were absent, } \\
\text { and further found no effect of } \\
\text { herbivores on mean grass height. }\end{array}$ \\
\hline More dead material. & $\begin{array}{l}\text { No. Less sheep grazing and less deer } \\
\text { grazing was associated with a } \\
\text { reduction in the abundance of dead } \\
\text { material. }\end{array}$ & $\begin{array}{l}\text { Low to moderate evidence; field } \\
\text { results might relate to sampling } \\
\text { methods (only top of sward } \\
\text { sampled; sampling of patches of } \\
\text { burned dwarf shrub might have } \\
\text { influenced results). }\end{array}$ & $\begin{array}{l}\text { Miller et al. (2010) support the } \\
\text { prediction, but Ter Heerdt et al. } \\
\text { (1991) suggest the increase is only } \\
\text { temporary and seasonal. }\end{array}$ \\
\hline Less bare ground. & $\begin{array}{l}\text { NS (sheep dung alone). Less deer } \\
\text { grazing was, however, associated } \\
\text { with a reduction in the amount of } \\
\text { bare ground. }\end{array}$ & - & $\begin{array}{l}\text { Miller et al. (2010), Bullock and } \\
\text { Pakeman (1997), and Shaw et al. } \\
\text { (2010) all agree with the prediction. }\end{array}$ \\
\hline $\begin{array}{l}\text { More structure in vegetation mosaics, } \\
\text { less structure in heathlands. }\end{array}$ & $\begin{array}{l}\text { Only overall structural heterogeneity } \\
\text { was examined. Less sheep grazing } \\
\text { and less deer grazing was } \\
\text { associated with a reduction in } \\
\text { structural heterogeneity. }\end{array}$ & - & $\begin{array}{l}\text { Adler et al. (2001) support the field } \\
\text { results and part of the prediction, } \\
\text { finding that heterogeneity often } \\
\text { increases with grazing. }\end{array}$ \\
\hline
\end{tabular}

${ }^{1} \mathrm{NS}$ indicates not significant. 
(logistical constraints precluded the study team from including these groups in the study). The predictions chosen to develop into indicators therefore were those with general applicability to submontane habitats and that were logistically practical.

Overall, the participants' predictions were invaluable for generating hypotheses and focusing on the most suitable variables to measure rapidly in the field. However, in this instance the participants' predictions alone were not sufficient to be used directly without supporting field data. The situation is complicated by the apparent increase in deer abundance where sheep grazing is reduced. Reviewing the results relating to reduced sheep grazing only (i.e., ignoring responses relating to apparent changes in deer populations for the moment) the field results concur with the predictions in three of nine cases (Table 6: dwarf shrubs, vegetation height, and structural heterogeneity). Field study results were nonsignificant in a further four cases (voles, sweet grasses, herb species, and bare ground), and in two cases (dead material and rough grasses), the field study produced the opposite results to those predicted.

The apparent decrease in dead material as sheep and deer grazing reduced might be a genuine finding - an indication perhaps that the actual level of grazing by deer in the "lightly" grazed areas was being underestimated, or that in more heavily grazed areas the previous season's dead material, normally hidden below the sward surface, was being revealed. However it is more likely to be a spurious result caused, at least in part, by the sampling of patches of burned heather at some sites. If the total amount of dead material in the sward, including the litter layer, had been sampled (rather than just the top of the sward), it is possible that reduced grazing would have been associated with increased dead material. There are various fates that can meet growing plant material and influence the extent to which a "thatch" of standing dead material develops: 1) it can be eaten by grazing animals, or 2) not be eaten but die, break off, and be incorporated into the litter layer locally, or 3) die, break off, and be blown away, or 4) die and remain standing in situ. On these relatively high and exposed Scottish sites, uneaten material will likely desiccate and be blown away, minimizing the apparent impact of reduced grazing on the amount of dead material. Alternatively, as indicated by Ter Heerdt et al. (1991), the net buildup of dead matter can "self regulate" every year as the decomposition of last years remaining material equals the production of new dead material in late summer and autumn.

The change in relative abundance of sweet grasses, rough grasses, and dwarf shrubs in response to reduced grazing is likely to be significantly affected by their starting abundances (Hulme et al. 1999). In the present study, heather, the commonest of the dwarf shrubs, was almost ubiquitous, occurring somewhere in the sampled transects at all but four subsites. Where heather is present, even as small plants suppressed within a grassy sward, it has the potential to expand at the expense of whatever other vegetation is dominant, if grazing is reduced (Hulme et al. 2002). In this study, increases in dwarf shrubs at the expense of the rough grasses were observed with negligible change in the sweet grasses. If dwarf shrubs had been excluded from the vegetation by a prolonged history of heavy grazing, or if soil conditions were unsuitable for them, changes in response to reduced grazing would probably involve an increase in rough grasses at the expense of sweet grasses. The professionals are therefore not wrong in predicting increases in both dwarf shrub and rough grasses in response to reduced grazing; it is simply that these phenomena are context-specific. In this study, herb species collectively did not show significant differences in abundance in relation to reduced sheep grazing. It is likely that individual herb species, or groups of similar herb species, will increase or decrease in response to changes in grazing and competition with other plants. For instance, Miller et al. (2010) found a reduction in annual forbs (herbs) and slight increases in perennial forbs where sheep were excluded from small plots. De Gabriel et al. (2011) found reduced plant diversity at the site level where sheep grazing was absent. Similarly, Virtanen et al. (2002) found that although the cessation of deer grazing had little impact on the most unproductive communities, there was a marked decline in species richness in productive grasslands on the Isle of Rum, off the west coast of Scotland.

In this study, reduced sheep grazing did not have a statistically significant impact on observed vole signs, probably because the sample size was too small. However, a nonsignificant trend was that voles were negatively related to both sheep and deer dung. Other workers (Hope et al. 1996; Smit et al. 2001; Steen et al. 2005; Evans et al. 2006) found significant increases in voles when grazing was reduced, because they are thought to benefit from the increased food supply and greater protection from predators provided by taller vegetation.

Bare ground was predicted by the professionals to decrease in response to reduced sheep grazing, but our field results suggested that bare ground presence was positively associated with deer rather than sheep. Miller et al. (2010), working on an alpine dwarf-herb community in the Scottish Highlands, found that bare ground decreased in small plots protected from grazing by sheep and remained more or less constant where sheep grazing was maintained. Bare ground is a potentially useful indicator in high rainfall rangelands because swards are often closed canopy except where grazing herbivores have disturbed the turf layer with their feet or where landslips have occurred. Areas where soil is exposed provide microsites that allow the establishment of new seedlings (Shaw et al. 2010), which otherwise might not be able to compete with established vegetation. Bare ground has been observed to increase with grazing both by domestic stock (e.g., Bullock and Pakeman 1997; McEvoy et al. 2006) and by wild deer (Pellerin et al. 2006) in other habitats.

Vegetation height was found to be related to both observed sheep and deer abundance in this study. The predicted increase in tall, homogeneous heath vegetation could have several effects. Tall vegetation can insulate soils, slowing the speed of warming in spring and increasing the soil moisture content (Olofsson et al. 2008). Cooler soils (and the reduction of nutrient input from excreta) can reduce nutrient cycling, resulting in decreased availability of nutrients to plants in the short term (Olofsson et al. 2007). Increases in vegetation height in response to reduced sheep grazing have been observed by other workers (e.g., Hope et al. 1996; Miller et al. 2010; Mayer et al. 2009). However, DeGabriel et al. (2011) found that heather was shorter where sheep were absent, and further, found no effect of herbivores on mean grass height.

One issue that the participants highlighted, but were relatively unsure about, was the interaction between reduced 
sheep grazing and vegetation structure. Analysis of the field results showed that the sheep and deer dung indices were collectively significantly positively correlated with the structural heterogeneity index, whereas the model using the sheep dung index alone was nonsignificant. This suggests that reductions in overall grazing pressure result in reductions in heterogeneity. Given the high level of uncertainty shown by the professional groups, and the importance of vegetation heterogeneity for a range of bird and invertebrate groups (Dennis et al. 1998; Pearce-Higgins; Grant 2002, 2006), further joint learning with stakeholders and further development of field methods on structural heterogeneity would be desirable.

In their review, Adler et al. (2001) found that grazing increased spatial heterogeneity, although only in situations where the spatial pattern of grazing was greater than the preexisting spatial pattern of the vegetation. Adler et al. (2001) compared grazed and ungrazed situations, but did not review varying intensities of grazing. It is possible that structural heterogeneity on rangelands might have a curved overall relationship with grazing intensity, with the lowest structural heterogeneity in those environments with either very heavy (e.g., Augustine et al. 2012) or very light grazing and highest structural heterogeneity at moderate levels of grazing. The professionals' apparently conflicting predictions about vegetation structure (more structure in mosaics, less structure in heathlands) could reflect this.

One of the findings of this study was that deer abundance appeared to be higher where sheep grazing had been reduced. DeGabriel et al. (2011) found a similar pattern in a study in upland Scotland with deer dung counts being higher on sites where sheep had been removed than where sheep were present. Where deer have the option to avoid sheep, they might well do so, but evidence for this is largely anecdotal (Albon et al. 2007). Although it is possible that deer birth rates have increased in areas where sheep have been reduced or removed, it is more likely that deer from adjacent sheep-grazed areas have changed their home range to concentrate on the areas with fewer sheep.

Although deer can be considered more as browsers than grazers (Hofmann 1989) and are less likely to target grass patches for grazing than sheep (Clarke et al. 1995; Albon et al. 2007), they have broadly similar grazing preferences to sheep (Osborne 1984; Hester et al. 1996). Deer might therefore limit the potential effects of sheep reduction if their populations increase. However, deer behave and react to human disturbance differently than do sheep (Palmer and Hester 2000); they range further (Palmer et al. 2003), are less managed, and are usually not given supplementary feed or anthelmintics (Milner et al. 2002). It is therefore unlikely that wild deer populations would fully compensate for the decline in sheep because they are unlikely to reach the local densities that sheep have historically attained.

\section{Other Impacts of Reduced Grazing}

If sheep grazing is reduced and deer populations do not fully compensate for the reductions, (i.e., an overall decrease in grazing pressure), then vegetation height and abundance of dwarf shrubs will likely increase. Whether deer populations alone are sufficient to maintain current vegetation heterogeneity remains to be seen. With higher deer populations and taller vegetation, ticks, and the diseases carried by them (e.g., Lyme disease, Louping ill virus, and tick-borne fever), are likely to become a more important issue (Gilbert 2010). In areas without populations of wild deer, reductions in sheep populations are likely to have a marked impact on vegetation height and structure.

Changes to habitats and associated species will have effects that impact at the ecosystem scale, whereas changes to the relative abundance of the different species groups will affect not only biodiversity as a whole, but also wild-fire risk, soil erosion, and accumulation patterns, water retention, and by extension, the future usefulness (either positively or negatively) of the landscape. The longer-term impacts are a subject of debate, with predictions including increased shrub then woodland cover (Miles 1988) or the continuation of an open landscape with an increase in mire communities (Fenton 2008). The long-term outcome might depend on the local impact of reduced herbivory on changes in nutrient cycling (Olofsson et al. 2007). It is likely that the perceived aesthetic impression of the hills will change, with vistas altering as landscape scale heterogeneity potentially increases at the same time as local scale heterogeneity decreases. Inevitably, under reduced sheep grazing, there will be some species that benefit from the new conditions, and others might suffer (SAC 2008). The overall assessment of whether reduced sheep grazing is "good" or "bad" for upland areas therefore is a value judgment.

\section{Applicability of Field Methods}

Where general information is sought about vegetation type, location, and structure, the rapid assessment of transects at numerous paired sites was demonstrated to be a useful tool. The quadrat-based methods were found to be unhelpful using a sample size of just five quadrats per subsite. Neither of the predictions tested using the quadrat data (more voles, change in herb species) generated significant results. It is likely that five quadrats per subsite provided insufficient statistical power, because there is evidence in the literature that voles do increase when sheep grazing is reduced (Hope et al. 1996; Smit et al. 2001; Steen et al. 2005; Evans et al. 2006). Even the results generated using the transect-based methods need to be interpreted cautiously. For example, in this study only dead material at the sward surface was recorded. The build-up of thatch as a first indication of undergrazing was not observed during this study even where sheep grazing had been drastically reduced. The field method used (i.e., the Hill Farm Research Organization [HFRO] sward stick) precluded the sampling of dead material below the sward surface. If dead material throughout the sward was sampled, it is possible that the professionals' prediction (less grazing results in more dead material) would be supported. Therefore, finding a robust yet rapid method of assessing the total amount of dead material (thatch) is a challenge for future studies; if cross-compliance rules continue to specify thatch build-up as an issue, this will be doubly important.

The method used for assessing vegetation structure was developed from work by Phillips (1989). In this study structural heterogeneity (the total number of different dominant + subdominant structural types present across a subsite) was found to decline with reduced sheep grazing and reduced deer grazing. Although the index used here is simple, the authors 
believe it is robust and applicable even though others have used more complicated definitions of heterogeneity. For example, Scimone et al. (2007) defined sward structure in terms of divergence from an expected distribution, so that the value calculated for heterogeneity increased when a few types had high frequency and decreased when all types had an even frequency. Tichit et al. (2005) used an index created by Burel and Baudry (1999), derived from the Shannon formula. This index rewards cases where a transect contains many different patch heights, but cases where a transect has many distinct patches of only a few types are assigned low values of heterogeneity (Tichit et al. 2005).

Finally, this study used paired sites where sheep had been reduced or removed from one area and maintained at another. Historical information on the vegetation conditions prior to the reduction was not available; therefore, it cannot be claimed that differences detected are solely due to changes in grazing pressure. It is possible that there were significant differences between subsite pairs before sheep grazing was reduced in one area, and that these differences contributed to the decision to remove sheep from one of the subsites. The length of time since the reduction in sheep numbers occurred will inevitably influence the vegetation condition, but there were not enough samples in the study to allow this variable to be included in the models. Further, the nonrandom selection of sampling areas, the relative season, and limited time period when observations were made also might have had a bearing on the measurements collected. Additional sampling in different areas over longer time periods could be easily incorporated within similar or follow-up studies.

Another limitation of the field study is that only five transects were sampled per subsite; given the sporadic nature of burned patches, this might be insufficient and could have influenced the results on dead material. Ideally, sites where burning was being practiced for game management alone would not have been sampled, but this would have reduced the number of sites available for study considerably. Being a natural rather than experimental study, it is inevitable that problems appeared, such as the overall higher grazing pressure at some sites where sheep grazing had been reduced.

\section{Future Trends}

Sheep populations, over the next few years at least, will likely continue to decline as a result of the post-production-focused modifications to the Common Agricultural Policy implemented in 2005, which favor good environmental stewardship over production (Albon et al. 2007). In extensive farming landscapes such as in Scotland, the void created by the removal of domestic livestock could be filled by wild herbivores whose impact on upland habitats is currently still a matter of debate. The methodology used in this study would be applicable to other marginal upland areas of Europe with a strong presence of wild herbivores or could easily be modified, with guidance from local professional stakeholders, to those landscapes without large wild herbivores. In the wider European economic context, where upland livestock farming appears to be in serious decline, rapid and cost effective assessment tools such as the methodology presented here are urgently required to provide evidence of environmental and conservation impacts to land managers and policy makers. Indeed, EU support payments for hill farming and marginal agriculture are likely to continue, but the focus might be more toward agri-environmental or socially-linked schemes, and the provision of public goods, such as biodiversity (Cioloş 2011).

\section{IMPLICATIONS}

The development of a professional-led set of biodiversity indicators has been tested. The method encourages group decision-making that helps to focus on those indicators that can be rapidly assessed in the field when limited time or resources preclude more detailed scientific studies. The participatory approach and subsequent field assessments proved to be a useful tool where the impacts of changes to rangeland agricultural practices need to be understood. The method presented can be easily adapted to other global landscapes as long as a representative group of professionals and stakeholders can be found and persuaded to participate.

It was found that reductions in sheep grazing did not always lead to the changes predicted by participating local professionals. The observed abundance of wild herbivores (red deer) explained many of the differences between sites and between predicted and actual results. However, a number of limitations in field study protocol were raised that might have affected the field results. Further, the requirement for recent historical knowledge concerning the management practices on such study sites (e.g., controlled burning or wildfires) was highlighted. Understanding the impacts of both domestic and wild herbivore populations, in combination, is critical to managing biodiversity interests in rangeland areas where domestic herbivores have had strong recent influence. However, the methodology developed need not be restricted to areas where large wild herbivores are present. Although the scope of the field study was limited, the results proved relevant and provided a novel opportunity for joint learning for the professional group and scientists involved. Moreover, this approach is part of a burgeoning trend of using local professional knowledge to guide scientific studies that can then offer pertinent and value-added assessment tools to stakeholders and policy makers. Clearly, landscape and conservation focused schemes, as examples for future support funding, will be reliant upon such concise methods to identify locations where grazing is essential to maintain habitat variation and viable populations of rarer species.

\section{ACKNOWLEDGMENTS}

The authors wish to thank the landowners and managers of the study sites, the professional and stakeholder groups involved in the study, and the National Trust for Scotland at Glencoe for hosting and support of the workshop. We are grateful to the anonymous reviewers for their helpful comments.

\section{LITERATURE CITED}

Adler, P. B., D. A. Raff, and W. K. Lauenroth. 2001. The effect of grazing on the spatial heterogeneity of vegetation. Oecologia 128:465-479. 
Albon, S. D., M. J. Brewer, A. O’Brien, A. J. Nolan, and D. Cope. 2007. Quantifying the grazing impacts associated with different herbivores on rangelands. Journal of Applied Ecology 44:1176-1187.

Augustine, D. J., D. T. Booth, S. E. Cox, And J. D. Derner. 2012. Grazing intensity and spatial heterogeneity in bare soil in a grazing-resistant grassland. Rangeland Ecology \& Management 65:39-46.

Baldock, D., G. Beaufoy, F. Brouwer, and F. Godeschalk. 1996. Farming at the margins: abandonment or redeployment of agricultural land in Europe. London, UK, and The Hague, The Netherlands: Institute for European Environmental Policy (IEEP), Agricultural Economics Research Institute (LEI-DL0). 202 p.

Barthram, G. T. 1986. Experimental techniques: the HFRO sward stick. Biennial Report, 1984-1985. Penicuik, UK: Hill Farming Research Organisation. p. 29-30.

BoumA, J. 2001. The role of soil science in the land use negotiation process. Soil Use and Management 17:1-6.

BozzoLo, G. 2009. Politique agricole et pastorale en zone de montagne. Courrier de l'environnement de I'INRA 57:93-108.

Bracke, M. B. M., J. J. Zonderland, and E. J. B. Bleumer. 2007. Expert judgement on enrichment materials for pigs validates preliminary RICHPIG model. Applied Animal Behaviour Science 104:1-13.

Bullock, J. M., and R. J. Pakeman. 1997. Grazing of lowland heath in England: management methods and their effects on heathland vegetation. Biological Conservation 79:1-13.

Burel, F., And J. Baudry. 1999. Ecologie du paysage. Concepts, méthodes et applications. Paris, France: Technique et Documentation. $362 \mathrm{p}$.

Caballero, R. 2009. Stakeholder interactions in Castile-La Mancha, Spain's cerealsheep system. Agriculture and Human Values 26:219-231.

Cannon, J., and P. SuRJadi. 2004. Informing natural resources policy making using participatory rapid economic evaluation (PREV); the case of the Togean Islands, Indonesia. Agriculture Ecosystems and Environment 104:99-111.

CIoLos, D. 2011. The CAP beyond 2013—challenges and opportunities for European agriculture. Oxford Farming Conference; 6 January 2011; Oxford, UK. Available at: http://europa.eu/rapid/pressReleasesAction.do?reference=SPEECH/11/ $3 \&$ format $=H T M L \& a g e d=0$ \&language $=E N \&$ guilanguage $=e n$. Accessed 12 July 2012.

Clarke, J. L., D. Welch, and I. J. Gordon. 1995. The influence of vegetation pattern on the grazing of heather moorland by red deer and sheep. 1. The location of animals on grass heather mosaics. Journal of Applied Ecology 32:166-176.

DeGabriel, J. L., S. D. Albon, D. A. Fielding, D. J. Riach, S. Westaway, and R. J. Irvine. 2011. The presence of sheep leads to increases in plant diversity and reductions in the impact of deer on heather. Journal of Applied Ecology 48:1269-1277.

Dennis, P., M. R. Young, And I. J. Gordon. 1998. Distribution and abundance of small insects and arachnids in relation to structural heterogeneity of grazed, indigenous grasslands. Ecological Entomology 23:253-264.

[ESRI] Environmental Systems ReSearch Institute. 2007. ArcMap GIS software, edition 9.2. Redlands, CA, USA: Environmental Systems Research Institute, Inc. 528 p.

Evans, D. M., S. M. Redpath, D. A. Elston, S. A. Evans, R. J. Mitchell, and P. Dennis. 2006. To graze or not to graze? Sheep, voles, forestry and nature conservation in the British uplands. Journal of Applied Ecology 43:499-505.

Fenton, J. H. C. 2008. A postulated natural origin for the landscape of upland Scotland. Plant Ecology \& Diversity 1:115-127.

French, K. 2006. Group facilitation skills: a toolbox for effective meetings. Edinburgh, UK: Kate French Associates. 16 p.

GILBERT, L. 2010. Altitudinal patterns of tick and host abundance: a potential role for climate change in regulating tick-borne diseases? Oecologia 162:217-225.

Gordon, I. J., A. J. Hester, and M. Festa-Bianchet. 2004. The management of wild large herbivores to meet economic, conservation and environmental objectives. Journal of Applied Ecology 41:1021-1031.

Grant, S. A., L. Torvell, E. M. Sim, J. L. Small, and R. H. Armstrong. 1996. Controlled grazing studies on Nardus grassland: effects of between-tussock sward height and species of grazer on Nardus utilisation and floristic composition in two fields in Scotland. Journal of Applied Ecology 33:1053-1064.

Hallanaro, E. L., and M. B. Usher. 2005. Natural heritage trends: an upland saga. In: D. B. A. Thompson, M. F. Price, and C. A. Galbraith [EDS.]. Mountains of Northern Europe: conservation, management, people and nature. Edinburgh, UK: TSO Scotland. p. 307-324.
Hester, A. J., F. J. G. Mitchell, I. J. Gordon, and G. J. Baillie. 1996. Activity patterns and resource use by sheep and red deer grazing across a grass/heather boundary. Journal of Zoology 240:609-620.

Hill, M. O., D. F. Evans, and S. A. Bell. 1992. Long-term effects of excluding sheep from hill pastures in North Wales. Journal of Ecology 80:1-13.

Hofmann, R. R. 1989. Evolutionary steps of ecophysiological adaptation and diversification of ruminants: a comparative view of their digestive system. Oecologia 78:443-457.

Hogan, C. 2003. Practical facilitation: a toolbox of techniques. London, UK: KoganPage. $482 \mathrm{p}$.

Hope, D., N. Picozzı, D. C. Catt, and R. Moss. 1996. Effects of reducing sheep grazing in the Scottish Highlands. Journal of Range Management 49:301-310.

Hulme, P. D., B. G. Merrell, L. Torvell, J. M. Fisher, J. L. Small, and R. J. Pakeman. 2002. Rehabilitation of degraded Calluna vulgaris (L.) Hull-dominated wet heath by controlled sheep grazing. Biological Conservation 107:351-363.

Hulme, P. D., R. J. Pakeman, L. Torvell, J. M. Fisher, and I. J. Gordon. 1999. The effects of controlled sheep grazing on the dynamics of upland Agrostis-Festuca grassland. Journal of Applied Ecology 36:886-900.

[IEeP] Institute for European Environmental Policy and Veenecology. 2005. Land abandonment-causes, extent and impact. In: G. van Dijk, A. Zdanowicz, and R. Blokzijl [EDS.]. Land abandonment and biodiversity in relation to the 1st and 2nd pillars of the EU's Common Agricultural Policy. Outcome of an international seminar; 7-8 October 2004; Sigulda, Latvia. Utrecht, the Netherlands: DLG Service for Water and Land Management. p. 23-32.

Knapp, C. N., M. Fernandez-Gimenez, E. Kachergis, and A. Rudeen. 2011. Using participatory workshops to integrate state-and-transition models created with local knowledge and ecological data. Rangeland Ecology \& Management 64:158-170.

Latham, J., B. W. Staines, and M. L. Gorman. 1996. The relative densities of red (Cervus elaphus) and roe (Capreolus capreolus) deer and their relationship in Scottish plantation forests. Journal of Zoology 240:285-299.

MacDonald, A., P. Stevens, H. Armstrong, P. Immirzi, and P. Reynolds. 1998. A guide to upland habitats: surveying land management impacts. 1. Background information and guidance for surveyors. Edinburgh, UK: Scottish Natural Heritage. 230 p.

MacDonald, D., J. R. Crabtree, G. Wiesinger, T. Dax, N. Stamou, P. Fleury, J. Gutierrez LAZPITA, AND A. GiBon. 2000. Agricultural abandonment in mountain areas of Europe: environmental consequences and policy response. Journal of Environmental Management 59:47-69.

Mayer, R., R. Kaufmann, K. Vorhauser, and B. Erschbamer. 2009. Effects of grazing exclusion on species composition in high-altitude grasslands of the Central Alps. Basic and Applied Ecology 10:447-455.

Mayle, B. A., A. J. Pearce, and R. M. A. Gill. 1999. How many deer? A field guide to estimating deer population size. Edinburgh, UK: Forestry Commission. $96 \mathrm{p}$.

McEvor, P. M., M. FleXen, And J. H. McAdam. 2006. The effects of livestock grazing on ground flora in broadleaf woodlands in Northern Ireland. Forest Ecology and Management 225:39-50.

MiLes, J. 1988. Vegetation and soil change in the uplands. In: M. B. Usher and D. B. A. Thompson [EDS.]. Ecological change in the uplands. Oxford, UK: Blackwell Scientific Publications. British Ecological Society Special Publication No. 7. p. 57-70.

Mlller, G. R., C. Geddes, and D. K. Mardon. 2010. Effects of excluding sheep from an alpine dwarf-herb community. Plant Ecology \& Diversity 3:87-93.

Milner, J. M., J. S. Alexander, and A. M. Griffin. 2002. A Highland deer herd and its habitat. London, UK: Red Lion House. 367 p.

Moravec, J., and R. Zemeckis. 2007. Cross compliance and land abandonment. Deliverable D17 of the CC Network Project, SSPE-CT-2005-022727. $25 \mathrm{p}$.

Morgan-Davies, C., and A. Waterhouse. 2008. Hill and upland areas: livestock farming changes and stakeholders preferences. In: E. Stockdale [ed.]. Shaping a Vision for the Uplands. Aspects of Applied Biology 85:49-55.

Morgan-Davies, C., A. Waterhouse, J. P. Holland, and C. Zografos. 2003. Assessing uptake of innovative hill land uses-retaining sheep alongside planting of new native woodlands. Scottish Forestry 57:211-215.

Norton, L. R., J. Murphy, B. Reynolds, S. Marks, and E. C. Mackey. 2009. Countryside survey: Scotland results from 2007. Edinburgh, UK: Centre for Ecology \& Hydrology, Scottish Government and Scottish Natural Heritage. 83 p.

Noss, R. F. 1990. Indicators for monitoring biodiversity: a hierarchical approach. Conservation Biology 4:355-364. 
Olofsson, J., C. de Mazancourt, and M. J. Crawley. 2007. Contrasting effects of rabbit exclusion on nutrient availability and primary production in grasslands at different time scales. Oecologia 150:582-589.

Olofsson, J., C. de Mazancourt, and M. J. Crawley. 2008. Spatial heterogeneity and plant species richness at different spatial scales under rabbit grazing. Oecologia 156:825-834.

Osborne, B. C. 1984. Habitat use by red deer (Cervus elaphus L.) and hill sheep in the West Highlands. Journal of Applied Ecology 21:497-506.

Pakeman, R. J., P. D. Hulme, L. Torvell, and J. M. Fisher. 2003. Rehabilitation of degraded dry heather [Calluna vulgaris (L.) Hull] moorland by controlled sheep grazing. Biological Conservation 114:389-400.

Palmer, S. C. F., and A. J. Hester. 2000. Predicting spatial variation in heather utilization by sheep and red deer within heather/grass mosaics. Journal of Applied Ecology 37:616-631.

Palmer, S. C. F., A. J. Hester, D. A. Elston, I. J. Gordon, and S. E. Hartley. 2003. The perils of having tasty neighbors: grazing impacts of large herbivores on vegetation boundaries. Ecology 84:2877-2890.

Pearce-Higgins, J. W., and M. C. Grant. 2002. The effects of grazing-related variation in habitat on the distribution of moorland skylarks Alauda arvensis and meadow pipits Anthus pratensis. Aspects of Applied Ecology 67:155-164.

Pearce-Higins, J. W., and M. C. Grant. 2006. Relationships between bird abundance and the composition and structure of moorland vegetation. Bird Study 53:112125.

Pellerin, S., J. Huot, and S. D. Cote. 2006. Long term effects of deer browsing and trampling on the vegetation of peatlands. Biological Conservation 128:316-326.

PHILLIPS, J. 1989. "Fingerprinting" of heather moorland: a rapid survey method for estates. Heather Trust annual report. Dumfries, UK: The Heather Trust. p. 9-10.

Pollock, M. L., C. J. Legg, J. P. Holland, and C. M. Theobald. 2007. Assessment of expert opinion: seasonal sheep preference and plant response to grazing. Rangeland Ecology \& Management 60:125-135.

RavnBorg, H. M., and 0. Westermann. 2002. Understanding interdependencies: stakeholder identification and negotiation for collective natural resource management. Agricultural Systems 73:41-56.

REED, M. S. 2008. Stakeholder participation for environmental management: a literature review. Biological Conservation 141:2417-2431.

RoDWELL, J. S. [ED.]. 1991. British plant communities. Volume 2: mires and heaths. Cambridge, UK: Cambridge University Press. 628 p.

RodwELL, J. S. [ED.]. 1992. British plant communities. Volume 3: grasslands and montane communities. Cambridge, UK: Cambridge University Press. 552 p.

Rogge, E., F. Nevens, And H. Gulinck. 2007. Perception of rural landscapes in Flanders: looking beyond aesthetics. Landscape and Urban Planning 82:159-174.
[SAC] Scottish Agricultural College. 2008. Farming's retreat from the hills. Edinburgh, UK: SAC Rural Policy Centre. 56 p.

Scimone, M., A. J. Rook, J. P. Garel, and N. Sahin. 2007. Effects of livestock breeds and grazing intensity on grazing systems: 3 . Effects on diversity of vegetation. Grass and Forage Science 62:172-184.

ScotTISH EXECUtIVE. 2005. Cross compliance notes for guidance. Edinburgh, UK: Scottish Executive. Available at: http://www.scotland.gov.uk/Publications/2005/ 12/0990918/09199. Accessed 21 April 2011.

Scottish Government. 2010. Abstract of Scottish agricultural statistics 1982 to 2009. Edinburgh, UK: Scottish Government. Available at: http://www.scotland.gov.uk/ Publications/2010/03/16160036/0. Accessed 21 April 2011.

Shaw, R. F., G. R. Iason, R. J. Pakeman, and M. R. Young. 2010. Regeneration of Salix arbuscula and Salix lapponum within a large mammal exclosure: the impacts of microsite and herbivory. Restoration Ecology 18:1-9.

Smit, R., J. Bokdam, J. Den Ouden, H. Olff, H. Schot-Opschoor, and M. SchriJvers. 2001. Effects of introduction and exclusion of large herbivores on small rodent communities. Plant Ecology 155:119-127.

Soliva, R., K. Ronningen, I. Bella, P. Bezak, T. Cooper, B. E. Flo, P. Marty, and C. Potter. 2008. Envisioning upland futures: stakeholder responses to scenarios for Europe's mountain landscapes. Journal of Rural Studies 24:56-71.

Steen, H., A. Mysterud, and G. Austrheim. 2005. Sheep grazing and rodent populations: evidence of negative interactions from a landscape scale experiment. Oecologia 143:357-364.

Stllma, E. S. C., B. Vosman, H. Korevaar, M. M. Poel-Van Riuswijk, A. B. Smit, and P. C. StRUIK. 2007. Designing biodiverse arable production systems for the Netherlands by involving various stakeholders. Netherlands Journal of Agricultural Science $55: 1-20$

Ter Heerdt, G. N. J., P. Bakker, And J. De Leeuw. 1991. Seasonal and spatial variation in living and dead plant material in a grazed grassland as related to plant species diversity. Journal of Applied Ecology 28:120-127.

Tichit, M., D. Durant, and E. Kernéls. 2005. The role of grazing in creating suitable sward structures for breeding waders in agricultural landscapes. Livestock Production Science 96:119-128.

VAN DER WAL, R. 2006. Do herbivores cause habitat degradation or vegetation state transition? Evidence from the tundra. Oikos 114:177-186.

Virtanen, R., G. R. Edwards, and M. J. Crawley. 2002. Red deer management and vegetation on the Isle of Rum. Journal of Applied Ecology 39:572-583.

VSNı. 2007. Genstat software version 10. Hemel Hempstead, UK: VSN International Ltd.

Wilson, E. O., and F. M. Peter [eds.]. 1988. Biodiversity. Washington, DC, USA: National Academy Press. $521 \mathrm{p}$. 